\title{
A cultura visual religiosa como linguagem religiosa própria: propostas de leitura
}

Religious visual culture as its own religious language: reading proposals

Helmut Renders *

\begin{abstract}
Resumo
O artigo apresenta a investigação de culturas visuais religiosas dentro do conceito de línguas religiosas, introduzido na área de Ciências Religiosas e Teologia e incluído em sua árvore do conhecimento. Ao fazer isso, essa linguagem religiosa é considerada uma linguagem própria e distinta das linguagens textuais, e que, por essa necessidade, requer uma atenção especial. Num segundo e terceiro momento, considerando a composição da área 44 como Ciências da Religião e Teologia, possíveis ênfases e abordagens das culturas visuais são feitas para ambos os campos de pesquisa. Para isso, distingue-se a cultura visual como uma linguagem das ciências da religião na perspectiva de línguas e narrativas sagradas e uma linguagem religiosa da teologia no sentido de símbolos visíveis e impactantes. Numa retrospectiva, o texto apresenta os movimentos de elaboração deste campo de estudo na área como uma investigação de aspectos e expressões da religião muito pouco investigada e mapeia, pontualmente, suas epistemologias subjacentes e possíveis formas de aplicação. Com isso, o artigo fornece um acesso alternativo à dinâmica performativa das religiões e aos fenômenos do encantamento.
\end{abstract}

Palavras-chave: Brasil; teoria da religião; linguagens religiosas; cultura visual religiosa; interpretação de imagens religiosas.

\begin{abstract}
The article presents the investigation of religious visual cultures within the concept of religious languages, introduced in the area of Religious Sciences and Theology, and included in its tree of knowledge. By doing so, this religious language is considered a language of its own and distinct of textual languages, and which by this need requires an unique attention. In a second and third moment, considering the composition of the area 44 as Sciences of Religion and Theology, possible emphases and approaches of visual cultures are made for both fields of research. For this, it distinguishes visual culture as a language of the sciences of religion from the perspective of sacred languages and narratives, and a religious language of theology in the sense of visible and impactful symbols. In a retrospective, the text presents the movements of the elaboration of this field of study in the area as an investigation of aspects and expressions of religion very little investigated and maps, punctually, its underlying epistemologies and possible forms of application. By this, the article provides an alternative access to the performative dynamics of religions and the phenomena of enchantment.
\end{abstract}

Keywords: Brazil; theory of religion; religious languages; religious visual culture; interpretation of religious images.

Artigo submetido em 15 de junho de 2019 e aprovado em 27 de agosto de 2019.

* Doutor em Ciências da Religião pela UMESP. Professor da UMESP. País de origem: Alemanha. E-mail: helmut.renders@metodista.br 


\section{Introdução}

O VI Colóquio do Grupo de Pesquisa Religião e Cultura do PPGCR PUC Minas dedicou-se ao tema “Teorias da Religião” e faz parte de um ciclo de eventos dos Programas de Pós-graduação da área Ciências da Religião e Teologia que ocorreram ou ainda ocorrerão em 2018. Em conjunto encara-se o desafio de, no mínimo, revisitar, senão, reconstruir coletivamente as bases teóricas de uma área de conhecimento só recentemente reconhecida formalmente pela CAPES (TEIXEIRA, 2001; CRUZ; MORI, 2001; USARSKI, 2006; CAMURÇA, 2008; NOGUEIRA, 2012; MARANHÃO FILHO, 2013; NOGUEIRA, 2015; ENGLER; STAUBERG, 2013; SILVEIRA, 2016; 2018, p. 7398). Portanto, o nosso esforço coletivo vem em uma boa hora e é necessário por diversas razões, internas e externas. Primeiro, observa-se que a área e seus programas afiliados passam por significativas recomposições dos seus quadros. A primeira geração do corpo docente desses programas está se aposentando e isso representa um momento oportuno de refletir sobre seu legado, sobre o que nos uniu e une e o que nos trouxe até o reconhecimento da área. Por outro lado, não foram todas tarefas feitas ou satisfatoriamente resolvidas e novos desafios requerem uma ampliação de perspectivas. ${ }^{1}$ Há desafios internos quanto à convergência das epistemologias das ciências da religião e da teologia. Há desafios externos lançados pelo mundo acadêmico que tem o direito de saber como a área mesma se entende no cânon das ciências. Há a necessidade de explicar com clareza à sociedade civil - que afinal financia estudos da(s) religiões por bolsas ou auxílios de pesquisa - para quê essas verbas são necessárias, se estes investimentos são eventualmente tanto zwecklos como sinnvoll. ${ }^{2}$ E há temas novos, que estão chegando nos Programas de Pós-Graduação da[s] Ciência da[s] Religi[ão/ões] e de Teologia - salvo meu engano, nenhum programa usa o plural “Teologias" - que requerem novas pesquisas e fundamentações teóricas próprias por ir além das fronteiras até então estabelecidas.

\footnotetext{
${ }^{1}$ Isso ficou evidente na discussão entre os/as coordenadores/as dos PPGs da área sobre a eventual necessidade de criar um nome alternativo para a área depois da sugestão do CTC da CAPES de chama-la "Teologia". Interessantemente, recuou a CAPES e ficou o nome "Ciências da religião e teologia". Entretanto, a própria área se organiza numa associação com o nome "Associação Nacional de Programas de Pós-Graduação de Teologia e Ciências da Religião" - e não o inverso...

${ }^{2} \mathrm{O}$ tema apareceu recentemente de novo numa mesa do Simpósio Internacional da ABHR.
} 


\section{A concepção de linguagens religiosas e os estudos da cultura visual religiosa}

Nossa pergunta inicial é se os debates ao redor de uma epistemologia da área fizeram considerações relevantes para os estudos da cultura visual religiosa. Em primeiro lugar, eu diria que a introdução da concepção "linguagens religiosas" representa um grande avanço, que inclusive para os estudos da cultura visual religiosa - mas não só - deu uma perspectiva nova e promissora. Até então, imagens foram de grosso modo entendidas por meio de categorias estéticas, às vezes, até como meras ilustrações, como uma outra forma de texto que se pode ler com as ferramentas da semiótica e da análise de discurso e, como símbolo. Essas aproximações trouxeram benefícios e resultados para a pesquisa acadêmica, mas, eventualmente, com a exceção da compreensão de imagens como símbolos, não atribuíram às imagens uma linguagem própria. Sem dúvida nenhuma, abriu a concepção de linguagens religiosas ou da religião (NOGUEIRA, 2012) pelo Programa de Pós-graduação em Ciências da Religião da UMESP3 as portas para novos olhares. Ele foi referenciado como título de seção no Compêndio de ciência da religião, editado pelos colegas João Décio Passos e Frank Usarski do curso de Ciências da Religião da PUC de São Paulo em 2013,4consecutivamente, integrado na árvore de conhecimento onde constam como "Ciências da linguagem religiosa" 5. O plural "Ciências..." possibilitou um novo além de uma só metodologia e um só uso preferencial, como documenta, entre outros, coletâneas especializadas em 2012 e 2015 (NOGUEIRA, 2012; 2015) e um dossiê como "Narrativas Sagradas e Linguagens Religiosas" na revista Horizonte em 2016.6

Era nessa perspectiva, então, que nós começamos, a partir de 2009, ler imagens considerando elas mesmas como "linguagens imagéticas da religião"

\footnotetext{
${ }^{3}$ Expressões parecidas, porém, não idênticas; ver: Júlia Miranda (1999), José Severino Croatto (2001) e Helmut Renders (2009, p. 373413).

${ }^{4}$ As seções do livro são "Epistemologia da Ciência da Religião, Ciências Sociais da Religião, Ciências Psicológicas da Religião, Ciências das Linguagens Religiosas e Ciência da Religião Aplicada“.

${ }^{5}$ Ciência da religião aplicada; Ciências da linguagem religiosa; Ciências empíricas da religião; Epistemologia das ciências da religião; História das teologias e religiões; Teologia fundamental-sistemática; Teologia prática; Tradições e escrituras sagradas.

${ }^{6}$ Conferir também o "Dossiê: Narrativas Sagradas e Linguagens Religiosas" na revista Horizonte, organizado por Paulo Augusto de Souza Nogueira, e as contribuições: "Religião e linguagem: proposta de articulação de um campo complexo" (NOGUEIRA, 2016, p. 240-261); "Linguagens religiosas e narrativas sagradas" (KONINGS, 2016, p. 236-239); "Narrativas Apócrifas e Linguagem Religiosa como memória e sentidos das comunidades cristãs primitivas, pela égide das teorias da linguagem" (IZIDORO, 2016, p. 262-283).
} 
(RENDERS, 2009, p. 373-413) ou a "cultura visual” como uma própria "linguagem da religião" (RENDERS, 2015, p. 67-84). Nesse campo maior identificamos também diversos linguais visuais particulares como a "religiocordis como linguagem da religião na iconografia jesuíta” (RENDERS, 2015, p. 1021-1050) ou, em termos mais gerais, "artefatos, imagens e logotipos como linguagens da religião" (RENDERS, 2015, p. 63-88). No mesmo ano dessa publicação, criamos o Grupo de Pesquisa CNPq “Cultura visual religiosa - RIMAGO” e o próprio PPG em Ciências da Religião da UMESP se dedicou ao tema nas suas Semanas de Estudos de Religião de 2015 ("Religião: Cultura Visual \& Cultura Material”7) e 2017 ("Imagens femininas de Deus e devoções marianas na América Latina"8). Nessa caminhada estreitamos laços com os colegas da área Etienne Alfredo Higuet ${ }^{9}$ (UEPA (20152018/ UFJF 2018)), Frederico Pieper da UFJF, e Joe Marçal Gonçalves dos Santos (UFS). Juntos organizamos desde 2015 Grupos de trabalho na "Semana de Estudos da Religião do PPG em Ciências da Religião da UMESP10, nos Simpósios da ABHR ${ }^{11}$ e nos congressos Internacionais da ANPTECRE12. Last but not least, publicamos no fim do ano na revista Numen da UFJF um dossiê "Cultura visual religiosa e cinema”, organizado por Frederico Pieper. Com esse primeiro dossiê específico chega-se em um novo nível de visibilidade dos estudos das culturas visuais religiosas como parte das linguagens religiosas, da religião ou das religiões como das religiões nas medias visuais, como o cinema, a televisão e os videoclipes.

\footnotetext{
${ }^{7}$ Na semana compartilhamos uma mesa com Jorge Miklos (UNIP), com o tema "A importância da Cultura Visual para os estudos de religião".

${ }^{8}$ Onde compusemos, junto com a Profa. Dra. Cara Mary S. Oliveira (UFPAR) uma mesa com o tema "A figura feminina nas pinturas, na azulejaria e nas gravuras religiosas barrocas católicas e protestantes: Europa e América portuguesa, séculos XVI a XIX".

${ }^{9}$ Higuet é um dos primeiros pesquisadores que estudava a relação entre arte e religião no PPG em Ciências da Religião da UMESP, junto com Jaci Maraschin (1930 d.C. -2009 d.C.). Quanto aos estudos da cultura visual, fez diversas contribuições. Além de orientar diversas dissertações e teses com o foco arte e religião, organizou em 2017 o "23 Seminário em diálogo com o pensamento de Paul Tillich: religião e artes visuais". Por enquanto, sua última contribuição é Higuet (2018, p. 126-160).

${ }^{10}$ GT Cultura Visual Religiosa, em 2015; em 2016, com Frederico Piper; em 2017, com Etienne Alfred Higuet.

11 25-29/07/2016: II Simpósio Internacional da ABHR / XV Simpósio Nacional da ABHR: GT 51: Religião, cultura visual, cinema[Coordenação Dr. Frederico Pieper, UFJF e Dr. Helmut Renders, UMESP Comentários: Dr. Arnaldo Érico Huff Júnior, UFJF; Dr. Joe Marçal Gonçalves dos Santos, UFS e Dr. Luís Américo Silva Bonfim, UFS; 11-14/10/2018: III Simpósio Internacional da ABHR / XV Simpósio Nacional da ABHR: GT Cultura visual, Religião e Cinema Coordenadores: Helmut Renders (UMESP), Etienne Alfred Higuet (UEPA) Comentários: Doutorando Altierez Sebastião dos Santos (UMESP).

${ }^{12}$ No IV Congresso Nacional da ANPTECRE (04-06/09/2013), o tema da cultura visual é ainda discutido na Sessão temática "12. Religião como Texto: Linguagens e Produção de Sentido" coordenada pelos Profs. Drs. Paulo Augusto de Souza Nogueira (UMESP), Pedro Lima Vasconcellos (PUC-SP); Douglas da Conceição (UEPA) e Rodrigo Franklin de Sousa (MACKENZIE). No V Congresso Nacional da ANPTECRE (09-11/09/2015) criamos a sessão temática "Cultura visual e religião" junto com Frederico Pieper Pires (UFJF) e Joé Marçal Goncalves dos Santos (UFS) o que repetimos na No VI Congresso Nacional da ANPTECRE.
} 
Em seguida, apontamos possíveis e desejadas contribuições dos estudos da cultura visual religiosa para a nossa área ciências da religião e teologia como um olhar que nos ajuda perceber entrelinhas de expressões religiosas históricas ou vitais, não suficientemente articuladas por textos sobre as religiões baseados em textos das religiões ou relatos de pessoas. Como os estudos da religião não têm um cânon metodológico para esse tipo de investigação estabelecido, fizemos empréstimos teóricos e metodológicos nas áreas da história da arte, da antropologia social, da comunicação social e dos estudos culturais.

\section{Linguagens religiosas e narrativas sagradas: a cultura visual religiosa com linguagem religiosa nas ciências da religião}

Os estudos da cultura visual religiosa, como parte ou dos estudos da estética da religião (na perspectiva alemã da ciência da religião) ou da cultura material (na perspectiva anglo-saxão de estudos teológicas e das ciências da religião), se dedicam aos estudos de fenômenos religiosos e das suas representações materiais e visuais numa perspectiva ampla. ${ }^{13}$ Primeiro, de fato, a cultura material e visual é muitas vezes o único artefato humano que nós temos que evidenciam práticas religiosas. Tudo isso começa com objetos supostamente usados para ritos em preparação da caça ou do plantio, pinturas, sinais e objetos encontrados juntos a pessoas enterradas. A cultura visual e a cultura visual religiosa parecem andar juntas desde uma fase muito cedo da humanidade, mesmo que nós muitas vezes não soubéssemos nada ou muito pouco sobre as práticas religiosas e seus subjacentes imaginários, cosmologias e crenças que envolveram esses objetos pequenos como figuras de animais ou enormes como as composições arquitetônicas de pedras erguidas de forma circular no Amapá.

Uma referência importante vem de Lucia Traut e Annette Wilke (2015). Em seu livro eles distinguem entre I - Técnicas de imaginação (p. 75-192); II - Espaços de imaginação (p. 193-270); III - Políticas de imaginação (p. 271-282) e a IV -

\footnotetext{
${ }^{13}$ Nós já orientamos pesquisas sobre a cultura visual do Vale do Amanhecer e do ambiente das culturas populares religiosas que transitem entre o cristianismo popular espiritismo e religiões afro.
} 
História da imaginação (p. 383-486). Trata-se, então, de uma abordagem antropocêntrica, ou, uma que foca nos seres humanos e suas técnicas, os espaços criados por ele ou ela, as políticas que regem esse imaginário e uma clareza quanto às supostas mudanças ocorridas ao longo do tempo. O propósito é "elaborar a imaginação como categoria chave e além disso estabelecê-la como critical term analítico da ciência e da estética da religião" (TRAUT; WILKE, 2015, p. 13) baseado na "tese subjacente 'nenhuma religião sem imaginação'” (TRAUT; WILKE, 2015, p. 9).

A imaginação representa uma categoria chave da religião e da ciência da religião, porque a imaginação é fortemente envolvida na formação do sentido religioso e porque a religião e a imaginação compartilham aspectos essenciais e se sobrepõem funcionalmente, enquanto elas fazem o não-presente presente e o transpõem para os mundos da experiência além dos limites espaciais, temporais e físicas, mas, ao mesmo tempo, porque exercem apenas influência social e criam esquemas de percepção cognitivo-afetivos através de meios sensuais, físicos e materiais. [...] Nem é a imaginação entendida como pura ilusão, nem o seu poder criativo idealizado de forma excessiva. [...] Com a elaboração sistemática e diferenciada da imaginação como critical term evidencia o volume, o alto potencial analítico-explicativo que possui uma profunda reflexão sobre a imaginação, o processo da imaginação e sobre as diversas formas culturais e dinâmicas históricas do processo (coletiva) da imaginação; por exemplo para captar os fenômenos da longuedurées - bem como detectar mudanças religiosas, explicar a eficiência ritualista e para iluminar a conexão interativa entre o indivíduo e a sociedade, no sentido de mundos e mundos de significado, somática e semântica. É a reciprocidade complexa entre a percepção interna e as sensações externas, entre a imaginação individual e a comunicação simbólico-cultural, que torna a imaginação em um assunto particularmente fecundo, especialmente, para a estética da religião (TRAUT; WILKE, 2015, p. 9-10).

\section{Outros valorizam o conceito da imaginação como contraponto ao conceito do imaginário. Segundo Dietmar Kamper, o imaginário}

[...] consiste em restos de sonhos, nostalgias, esperanças, visões, mas também em dejetos de programas fracassados, conceitos, projetos. Um lixo histórico na reciclagem da cultura. Seu tempo é o futuro do pretérito. Tudo o que é terá sido. Neste sentido, ele tem seu futuro sempre no passado. O imaginário, do ponto de vista interno, nunca aconteceu. Por fora, nega sua origem. Jamais pode parar. Tem uma eternidade fatal que força seus prisioneiros à compulsão pela imagem (KAMPER apud OLIVEIRA, 2014, p. 169). ${ }^{14}$

\footnotetext{
${ }^{14}$ Outras referências de Kamper, em ordem cronológica, são a sua contribuição à história da imaginação (KAMPER, 1981), seus Hieróglifos do tempo (KAMPER, 1988); Perder de imagem: na órbita do imaginário (KAMPER, 1994); Troca de horizonte (KAMPER, 2001).
} 
Portanto, "contra o imaginário, ajuda somente a força da imaginação" (KAMPER, 2001, p. 25) e "Na época do imaginário mundialmente dominante, toda transcendência é imaginada” (KAMPER, 2001, p. 113) A imaginação, então, é o lugar da esperança, do resgate, do avanço o progresso na vida. Isso se aplica também a imaginação religiosa que, da mesma forma como o imaginário, opera com imagens e metáforas.

Christoph Wulf move em sua obra "Homo Pictor: imaginação, ritual e aprendizado mímico num mundo globalizado de 2013 (RENDERS, 2014, p. 613619) e mais uma outra direção. O significado de "imaginação, ritual e aprendizado mimético" para o desenvolvimento humano estuda o autor desde a sua primeira ênfase de pesquisa em "Lógica e Paixão" que tratou do redescobrimento do corpo e dos sensos como da "história da alma" inclusive da "inescrutabilidade do sagrado". $\mathrm{Na}$ sua antropologia pedagógica ele discute a importância de rituais para a construção de coerência de grupos sociais sem reduzi-los aos seus aspectos funcionais, porém, destaca também seus aspectos estéticos, lúdicos e performativos. Rituais organizam e ordenam a realidade e possibilitam identificações. Vinicius Spricigo resume a ideia fundamental na sua apresentação:

\begin{abstract}
A globalização política, econômica e cultural implica a sobreposição e, muitas vezes, a hibridização do global e do local, colocando em questão a antropologia cultural entendida como a ciência do "estrangeiro" e pautada no estudo etnográfico e na diferença das culturas, e por conseguinte o eurocentrismo das ciências humanas. Em outras palavras, questiona ChristophWulf: o que nós, como seres humanos, temos em comum e quais são as nossas diferenças? (WULF, 2013, p. 9).
\end{abstract}

Wulf desenvolve o projeto de uma antropologia sincrônica que busca entender e destacar o "em comum" da humanidade, para fundamentar melhor a convivência em um mundo globalizado. Com as palavras do próprio autor da sua publicação Lógica e paixão: 
No centro da Antropologia histórica não está a natureza do homem, mas a diversidade histórico-cultural da vida humana. A Antropologia Histórica não é uma disciplina científica, mas, um modo de ver o fenômeno humano; menos o objeto é tema e mais a perspectiva sob a qual eles são trabalhados [...] Suas pesquisas são plurais e transdisciplinarmente organizadas; elas estão hoje no centro da ciência da cultura (WULF, 2002, p. 1103).

O seu livro Homo Pictor, o primeiro texto maior traduzido para o português brasileiro, representa uma introdução em diversas fases da pesquisa desenvolvida por ele. Ele é organizado em quatro capítulos: 1) Imaginação e mimesis; 2) Ritual, gesto e jogo; 3) Patrimônio cultural intangível; e 4) Aprendizado no mundo globalizado. O autor rejeita com boas razões a ideia segundo a qual, nas sociedades modernas com suas tendências de pressionar na direção da individualização e da autonomia da pessoa, ritos se tornariam supérfluos. Em vez disso afirma: “Cada mudança ou reforma de instituições e organizações também requer a transformação de rituais" (WULF, 2013, p. 90). Concordamos com isso e poderíamos como exemplo citar o campo religioso brasileiro e o imenso número de rituais e encontros recentemente criados. A importância de rituais e a sua força performativa se devem em parte por serem "performances [...] do corpo" (WULF, 2013, p. 95). Rituais criam comunidades e novas realidades sociais por envolver implicitamente os corpos dos participantes; eles encenam hierarquias sociais e estruturas de poder; rituais transcendem o tempo comum e são assim sentidos como sagrados (WULF, 2013, p. 102-113). Eles

[...] criam continuidade entre as tradições, as necessidades atuais e os desafios futuros. Mudando a sua encenação e significado, criam um equilíbrio entre tradições, ações presentes e necessidades futuras. [...] A realização de rituais não é uma simples atividade repetitiva, mas, um ato criativo e social que unifica distintos grupos sociais e que produz ordem social, coerência cultural e que é capaz de dominar o potencial da violência social (WULF, 2013, p. 160).

A importância das imagens e da imaginação na construção do sentido se aplica também à construção do sentido religioso, em sua proposta de construir per definitionem um sentido transcendente do cotidiano. Nas pinturas se exterioriza este mundo construído no interior do ser humano e na contemplação de artefatos religiosos inverte-se o processo e [re]constroem-se imaginários. Podemos 
descrever a religião como parte da "artificialidade natural" do ser humano, do processo de construir sentidos que o mero conhecimento técnico não satisfaz. ${ }^{15}$ Enquanto o aprendizado mimético como "processo de incorporação e atribuição de sentido de produtos culturais" é amplamente ocupado pela propaganda da indústria do consumo, criando e atendendo desejos artificialmente, a necessidade de construir sentidos além da lógica do mundo do consumo prevalece. Especialmente quando se fala do horizonte da sustentabilidade, requer-se uma nova visão do limite, inclusive um novo entendimento da morte como elemento necessário da própria vida biológica que se multiplica pela divisão de células. Ritos são, às vezes, ainda interpretados como fenômenos arcaicos de culturas consideradas primitivas. Como outros, Wulf fala de ritos nos estados modernos e sua dependência deles na construção do novo. Nas religiões acontece o mesmo. Quanto ao cristianismo, o catolicismo, o protestantismo (RENDERS, 2014, p. 350373) e o pentecostalismo brasileiros passam por intensas reritualizações, em parte provocadas pelos novos rituais neopentecostais, mas, não só. Alguns dos novos ritos procuram estabelecer novas relações entre as respectivas tradições e a religião contemporânea e pós-moderna. Novas festas, novos formatos de cultos, novos tipos de encontros espirituais são propostos para construir novos sentidos, às vezes para desconstruir antigos, às vezes para relê-los ou revitalizá-los.

Nestes ritos usa-se, normalmente, objetos que articulam e informam o contato com o transcendente. Para entender esses artefatos da cultura material e visual religiosa pode ser interessante ampliar também a nossa perspectiva. Para isso as distinções de pesquisadores como Gilian Rose (2002) são fundamentais. Ele propõe interpretar imagens e esculturas na tripla perspectiva das modalidades tecnológicas, composicionais e sociais. Entre os itens destacados pelo autor e as

\footnotetext{
${ }^{15}$ Heilmair (2015, p. 2) cita Christoph Wulf (HUPPAUF; WULF, 2009, p. 299), e comenta: "De forma semelhante, a teoria das imagens endógenas, isto é, das imagens mentais interiores, aquelas que habitam os nossos corpos, também esteve presente ao longo de toda a história do pensamento ocidental (WULF, 2009). Mas diferente do que ocorreu com as imagens exógenas, por serem de natureza fugaz e subjetiva, às imagens endógenas foram atribuídos diferentes nomes e significados, a saber: fantasia, imaginação, e no alemão Einbildugskraft (força da imaginação), além dos termos mais genéricos: imagens mentais e imagens endógenas. Não obstante, a relação entre imagens internas e externas é tema importante para a nova teoria, ou ciência da imagem, pois 'Quando falamos de imagens, surge a pergunta se nos referimos às imagens 'externas' ou 'internas'. O fato do conceito 'imagem' englobar ambas as possibilidades, expressa algo que é característico das imagens. Imagens 'externas' se voltam para as 'internas' e as imagens 'internas' para as 'externas'. Imagens são produtos da forçada imaginação (Einbildungskraft) enraizada no corpo humano vegetativo."
} 
aplicações possíveis para o campo do estudo das religiões destacamos os seguintes pontos:

- Quanto à modalidade tecnológica, favorecemos o aspecto da localização. Onde se encontra o objeto, a pintura, o símbolo ou o altar? Num espaço sagrado ou num museu, numa casa ou num escritório?

- Quanto à modalidade composicional, privilegiamos os aspectos da produção e da imagem em si.

- A modalidade social conduz nosso olhar para questões da produção (Quem? Quando? Para quê? Por quê?), da recepção (Como é interpretado? Por quem? Por quê?) e das condições da produção. Qual é a relação entre as fixações do sentido pelo projeto institucional, por exemplo, como parte de um projeto de colonização, e as tendências mitopoéticas que vinham de baixo (ECO, 2000) e criam novos sentidos e espaços até alternativos? Apesar da nossa ênfase nas representações em si, a questão da audiência precisa ser, no mínimo, mencionada. Existem evidências para releituras, preferencialmente coletivas, apesar da intenção do produtor a partir da realização do artista ou do fiel?

Um caminho de interpretação ou do estudo dos fenômenos religiosos relacionados com as culturas materiais e visuais religiosas radicalmente diferente aponta David Freedberg (1989). Ele parte da observação dos efeitos que objetos aparentemente podem ter sobre pessoas que se organizam ao seu redor - e que eles são usados para estabelecer e manter essa influência seja por meios de meditação ou contemplação. Nesse processo ele alega que pertence aos próprios objetos uma dimensão performativa, no sentido de um efeito "eficaz", até "poderoso". ${ }^{16}$ Logo depois perguntou William John Thomas Mitchell (2005) "O que querem as

\footnotetext{
16 'As teorias da performance relacionam esse 'efeito' também com os rituais. Stanley Tambiah se refere a ao caráter constitutivo e performativo em três sentidos: [...] em primeiro lugar, como performance linguística, em que dizer algo também está fazendo algo como um ato convencional; em segundo lugar, como um desempenho encenado que usa múltiplas mídias pelas quais os participantes experimentam o evento intensamente; e, em terceiro lugar, no terceiro sentido de valores indexais - sendo anexados e inferidos por atores durante a performance." (TAMBIAH apud ALBUQUERQUE, 2018, p. 91). A performance ritual, baseando-se em dispositivos dramáticos como atos de repetição verbal e física, representação de papéis, música, dança, adereços e trajes estabelecidos, é uma codificação e transmissão de informações e crenças mantidas por um grupo particular de indivíduos.
} 
imagens?"17.Essa linha de interpretação segue também outros historiadores da arte como Horst Bredekamp (2015, p. 13) quem se refere à "[...] vitalidade da imagem, com a possibilidade de 'fazer-me algo', incluindo o poder de ferir”, e Gottfried Boehm (1994), criador do conceito da "virada icônica". Em conjunto estabeleceu a partir daqui uma visão alternativa ou paralela a ideia do "ato falado" (speachact) de John Austin (1962) ou da "virada textual” (textual turn) de Richard Rorty (1992), pela primeira vez publicado em 1967. Estabeleceu-se a compreensão de que “imagens, não são 'somente' símbolos e códigos e mensagens conceituais eles nos desafiam a até o ponto que nós os amamos ou odiamos, em outra palavras eles exercitam um poder sobre nos" (BARTMANSKI, 2014, p. 164-181) ${ }^{18}$ o que Hans Belting (2007, introdução) leva à pergunta "se imagens tenham o seu próprio $\log 0{ }^{\prime \prime} 19$.

Apesar de que os estudos da religião e, especialmente, teológicos, podem questionar essa leitura para se aproximar demais às noções “mágicas” de artefatos na vida religiosa e dos seus objetos (MALINOWSKI, 2015) ${ }^{20}$, essa compreensão ganhou muita atenção na área da história da arte com retorno para a área das ciências da religião e da teologia. Afinal, a ideia da agência dos artefatos da cultura visual e material é muito viva nas religiões praticadas. Mas Bredekamp não pensa predominantemente na relação entre a arte e a religião. Para ele o uso político e militar (Guerra das imagens) e científico das imagens como imagens de poder requer a nossa atenção. Nós acresceríamos duas observações: primeiro, o uso de imagens se estende também ao campo da economia, seguindo ou o modelo

\footnotetext{
${ }^{17}$ Mitchell criou o termo "pictorial turn" (virada pictorial). Suas referências incluam obras de Marshall McLuhan (1969); Michel Foucault (2002) e a compreensão da iconologia segundo Erwin Panofsky, Norval Baitello Junior levou a pergunta de Mitchell para o campo da comunicação [Para que servem as imagens mediáticas? 2007], mas trabalha especialmente com Hans Belting e Aby Warburg. Ele contribuiu à discussão os conceitos da iconomania e da iconofagia. Baitello Junior (2014) trata com isso especialmente o papel das imagens na contemporaneidade. Não há dúvidas que imagens religiosas, mesmo antigas com seus significados antigamente bem delimitadas, sofrem na atualidade ressignificações parecidas. Importante é também a sua colaboração com Dietmar Kamper com que ele fez o seu doutorado.

${ }^{18}$ Uma observação do autor pode interessar especialmente quem estuda artefatos religiosos em uso “[...] o conceito de 'virada icônica', cunhado pelo filósofo alemão Gottfried Boehm, pode capturar mais efetivamente o sentido da vida atribuído aos objetos visuais do que W.J.T. A famosa 'virada pictórica' de Mitchell".

${ }^{19} \mathrm{Cf}$. também sua proposta de uma ciência das imagens em paralelo à linguística, a ciência da língua: Belting (2001).

${ }^{20}$ A capa do livro mostra uma máscara. Lamentamos essa redução criando um laço imagético entre o livro o editor. Outro campo clássico é do iconoclasmo e da iconolatria (cf. RENDERS, 2008, p. 87-107).
} 
socialista ou capitalista ${ }^{21}$ e em todos esses diversos usos ocorre muitas vezes o empoderamento das imagens por referências ao significado religioso de imagens. Finalizando esse parágrafo: as ciências da religião e a teologia podem se beneficiar dos autoquestionamentos de outras áreas como, por exemplo, a sociologia. ${ }^{22}$

\section{3 "Símbolos visíveis e impactantes da graça invisível": a cultura visual religiosa com linguagem religiosa na teologia}

David Morgan, de formação um historiador de arte, partiu, inicialmente, também da pergunta como seres humanos interagem com representações, símbolos ou espaços religiosos. ${ }^{23}$ Segundo os seus estudos, especialmente da cultura visual protestante dos EUA do século 19, a "piedade do olhar / do ver" pode ser descrita, em termos gerais, por dois caminhos distintos: o da empatia ou da simpatia. Segundo o autor, a empatia promove a compreensão de que todos somos imago Dei e que esta afirmação potencializa todas as nossas relações. Já a simpatia se satisfaz em alcançar certa sensação de familiaridade, proximidade sem promover igualdade: "A simpatia acabou destacando a associação de iguais a si mesmo e a extinção gradual de todos os outros.” A distinção de Morgan contribui para a nossa compreensão da forma como o ser humano, a partir da mística da piedade visual, se relacionou e relaciona com a realidade. Percebe-se também que a forma de construir a relação pelos caminhos da empatia ou simpatia não se restringe a uma só confissão ou denominação.

\footnotetext{
${ }^{21}$ Quando nós discutimos, por exemplo, o capitalismo como religião, como é feito pelos colegas Jung Mo Sung e Lauri Emilio Wirth, podemos acrescer que existe uma iconografia do capitalismo como religião.

22 Dominik Bartmanski (2014, p. 171) cita Wogan e comenta: "As comunidades imaginadas de Benedict Anderson, sem dúvida o trabalho sociológico mais influente sobre as formas como nos imaginamos nos mesmos como sociedades e nações, nunca trataram sistematicamente de questões de experiências pictóricas e mitologias culturais visualmente constituídas. Além disso, nem sequer representa a lingualidade totalmente, pois, de maneira típica de sua disciplina, marginalizava a oralidade".

${ }^{23}$ Mais recentemente, Morgan (2014, p. 85) foca mais na "agência dos objetos". Um texto que trabalha ainda os dois aspectos seria David Morgan (1996, p. 17-341).
} 
Tabela: Empatia e simpatia como movimentos distintos da "piedade do olhar e ver"

\begin{tabular}{|c|c|c|}
\hline & Empatia & Simpatia \\
\hline Descrição & $\begin{array}{l}\text { Projeção de si mesmo na situação de } \\
\text { um outro. }\end{array}$ & Harmonia de sentimentos entre pessoas. \\
\hline $\begin{array}{l}\text { Papel do } \\
\text { corpo }\end{array}$ & $\begin{array}{l}\text { Sofrimento parte da ênfase no corpo; } \\
\text { procura do sujeito de ser igual a } \\
\text { Cristo e projeção do Cristo no próprio } \\
\text { corpo do devoto; o corpo participa na } \\
\text { resposta humana de forma integral. }\end{array}$ & $\begin{array}{l}\text { Controle moral e a apresentação pública } \\
\text { de um sujeito santificado; impedimento } \\
\text { do sofrimento. }\end{array}$ \\
\hline $\begin{array}{l}\text { Efeito desta } \\
\text { forma } \\
\text { devocional }\end{array}$ & $\begin{array}{l}\text { Causa “identificações": entre Deus e } \\
\text { os sofridos; entre o sofrimento } \\
\text { humano e o sofrimento divino (de } \\
\text { Jesus Cristo). }\end{array}$ & $\begin{array}{l}\text { Mantém as hierarquias e dependências } \\
\text { intactas. }\end{array}$ \\
\hline Ação social & $\begin{array}{l}\text { Convivência; solidariedade; } \\
\text { identificação. }\end{array}$ & $\begin{array}{l}\text { Assistencialismo que mantém as } \\
\text { configurações sociais e culturais no } \\
\text { essencial intactas. }\end{array}$ \\
\hline $\begin{array}{c}\text { Seres } \\
\text { humanos }\end{array}$ & $\begin{array}{l}\text { Compõem uma família e uma só raça, } \\
\text { sendo todos e todas “imagem de } \\
\text { Deus”. }\end{array}$ & $\begin{array}{l}\text { Todos são distintos por raça, idade, classe } \\
\text { social. }\end{array}$ \\
\hline
\end{tabular}

Fonte: Elaborada pelo autor.

Temos, entretanto, a dúvida se a mudança qualitativa na forma de construir os relacionamentos para com Deus, descrita por Morgan, ocorreu realmente só na virada do século 19 ao século 20. Seja como for, a percepção do autor nos sensibiliza pelo fato de que o contínuo uso de imagens e metáforas pode tanto descrever o estado intato, de um tipo de mística, como uma ressignificação do símbolo aparentemente intacto. Ernst Panofsky apresentou uma forma sistemática do estudo de arte renascentista. Este olhar é mais distante das práticas religiosas e dos artefatos usados neles, mas, procura fazer a ponte entre uma interpretação mais fiel tanto ao contexto do surgimento e da criação do artefato da cultura visual como ao seu significado hoje em dia. Esse historiador da arte Erwin Panofsky, desenvolve este método no início do século 20 quando percebeu que os seus alunos e alunas não entendiam mais as linguagens simbólicas e alegóricas da arte renascentista. Para isso, conduzia o olhar para a imagem a partir de três passos 
que, até um certo grau, acompanham a distinção entre signo, significante e significado da semiótica de Charles Sanders Pierce (1839-1914). Para nós, o método oriundo da história da arte é um convite para investigar com mais precisão expressões da cultura visual religiosa, em busca de significados religiosos e teológicos distintos dos textos, mas, articulados pela cultura visual. Seu método partiu da arqueologia do saber, chamada nível pré-iconográfico, à obra como expressão da sua época (iconográfico) conhecimento contemporâneo (iconológico). Desenvolvida originalmente para a interpretação da arte renascentista, Panofsky (1986, p. 47-65) inicia com uma descrição pré-iconográfica, seguida de uma análise iconográfica e interpretação iconológica. Recentemente, Peter Burke sugeriu, entre as três abordagens para o estudo da cultura visual popular - o método iconográfico, o método regressivo e o método comparativo -, dedicar-se mais à proposta de Erwin Panofsky, considerando justamente as xilogravuras de Épinal às quais a nossa obra pertence:

A iconografia foi definida por um dos seus maiores praticantes, o falecido Erwin Panofsky, como "aquele ramo da história da arte que se interessa pelo tema ou significado das obras de arte, em oposição à sua forma”. [...] Não há por que não estudarmos dessa forma o imaginário popular, tal como se estudam as obras de arte produzidas para príncipes e nobres, quer olhemos as figuras de cerâmica de Staffordshire, as peças de madeira entalhada e colorida à mão feitas em Épinal ou as pinturas camponesas de Dalarna. (BURKE, 2010, p. 76). ${ }^{24}$

Na leitura teológica de uma obra como essa, em primeiro lugar, é preciso incluir, na procura de motivos anteriormente configurados, além de motivos da Antiguidade, motivos religiosos, isto é, a visualização de narrativas, metáforas e conceitos bíblico-teológicos. Acreditamos que o método de Panofsky pode ter um valor pedagógico interessante para os/as cientistas da religião e os/as teólogos/as. Apesar da sua aproximação, digamos, um pouco esquemática, Panofsky conduz o/a pesquisador/a a um estudo mais criterioso e detalhado de cada obra, o que favorece a descoberta da unicidade de sua narrativa visual. Já outro aspecto da contribuição de Panofsky é descrever o impacto das imagens no imaginário religioso pelo viés da memória, da identificação, da recepção e da releitura. Esta ênfase mais

\footnotetext{
${ }^{24}$ Burke cita Panofsky e se refere às xilogravuras de Épinal.
} 
antropocêntrica de sua teoria faz ela mais acessível ao mundo da ciência e, em parte, ao mundo protestante, especialmente calvinista. 25

Já para a interpretação da cultura visual “em uso” como parte das práticas piedosas ou religiosas, sejam representações mais eruditas ou populares, Panofsky não traz recursos suficientes. Ele nos informa bem, mas não reflete sobre o aspecto performativo da representação da cultura visual. Entretanto, justamente seu orientador de doutorado, Aby Warburg, pode preencher essa lacuna. Warburg interpreta obras a partir dos conceitos do Nachleben de motivos que compõem uma imagem e sua interpretação como Pathosformeln. No sentido mais restrito, Aby Warburg descreve como Nachleben a complexa relação entre a iconografia précristã, suas metáforas imagéticas, alegorias e narrativas visuais e a arte visual como tudo. ${ }^{26} \mathrm{O}$ acento de Nachleben não está em "formula”, mas em “paixão" e "carga emocional"; não está no conceito, mas no impulso. Não se trata de uma repetição formal de uma ou mais formas no sentido de uma cópia, mas, de um aspecto de um motivo que o manteve impactante e cativante. Entretanto, o empréstimo de Warburg requer mais um esclarecimento. Seguindo uma distinção de Friedrich Wilhelm Nietsche (1780), Warburg vincula Nachleben e Pathosformeln com o ethos dionisíaco pagão em oposição ao ethos apolíneo cristão. Já entendemos que Nachleben e Pathosformeln podem descrever da mesma forma aspectos intracristãos como a relação entre motivos clássicos do mundo cristão e o cristianismo contemporâneo, especialmente, a sua aparência na arte devocional e popular religiosa. Isso nos parece ainda mais relevante quando se trata de narrativas visuais da paixão de Cristo, de cenas do paraíso ou metáforas visuais como a Nova Jerusalém, a porta estreita ou a do inferno. Trata-se de motivos carregados de pathos - paixões, crises existenciais e, também, sonhos e esperanças.

\footnotetext{
${ }^{25}$ Conceitos como "ato icônico" (BREDEKAMP, 2015) lembram modelos da teoria iconográfica jesuíta (BOER; ENENKEL; MELION, 2016).

${ }^{26}$ As traduções encontradas dos conceitos contêm problemas significativas; Já Pathosformeln indica o aspecto performativo de um motivo, que se aproxima da compreensão de Horst Bredekamp (2015) do "ato icônico" ou de David Morgan (2014, p. 85) da "agência de objetos" (MORGAN, 2014. p. 83-86). As traduções de Nachlebenen encontradas na literatura inglesa e portuguesa não satisfeitam completamente, nem as formas mais literais - "sobrevivência" (survival), vida depois da morte (afterlife) - nem as formas mais interpretativas como "renascimento" (rebirth), ou "lembranças de coisas do passado" (rememberance of things past). Assim comenta também Giorgio Agamben: “O termo alemão Nachleben não significa propriamente 'renascimento', como foi muitas vezes traduzido, nem "sobrevivência". Ele implica a ideia daquela continuidade da herança pagã que, para Warburg, era essencial" (AGAMBEN, 1975, p. 85). Quanto ao significado original, propomos uma nova abordagem. Parece-nos que a palavra Nachleben acompanha as estruturas significantes de outras palavras como Nachkommen (descendentes) e Nachbeben (tremor menor que segue um terremoto).
} 


\section{Considerações finais}

Um tema como "A cultura visual religiosa como linguagem religiosa nas ciências da religião e na teologia” não se finaliza em algumas páginas. Tentamos identificar algumas encruzilhadas e identificar possíveis caminhos a serem tomados. Alegamos, primeiro, que as ciências da religião e a teologia no Brasil não deram à devida atenção ao assunto das expressões religiosas da cultura visual e onde eles deram sem conversar com interlocutores que acompanham a revolução da virada icônica em nosso mundo contemporâneo com resultados inspiradores para os estudos da religião. Por enquanto, a ordem é se apropriar da discussão estabelecida nas ciências afins a nossa área, porque ainda somos mais analfabetos iconológicos do que especialistas. Entretanto, a religião vivenciada faz parte da cultura cotidiana e ela interage com as consequências da "virada pictorial" ou a “virada icônica”. O que se descreve dessa forma está, por um lado, reafirmando ou privilegiando certas práticas religiosas e, por outro lado, transformando outras. Não vivemos mais numa era meramente iconológica, onde regem dinâmicas iconólatras, iconoclastas ou iconófilas, mas, em uma época iconomanica e iconofágica. Enquanto no cristianismo muitos protestantes e entre eles especialmente aqueles/as da tradição calvinista precisam ainda aprender as bases da iconologia todos/as temos a necessidades de entender as religiões na época da iconofagia e iconolatria.

Ignoramos neste texto que a área das ciências da religação e da teologia não chega nesse diálogo interdisciplinar totalmente com mãos vazias. As discussões sobre a iconologia, iconolatria e iconofilia podem servir como elemento crítico nessa conversa e, ao mesmo tempo, se beneficiar pela discussão. As reflexões da igreja sobre a beleza do símbolo da cruz ou do crucifixo abrem perspectivas distintas no campo da estética. Mas, isso não era o propósito desse exercício. E, provavelmente, há outras contribuições de outros sistemas religiosos para a compreensão e o estudo da cultura visual religiosa que nós ainda nem descobrimos. 


\section{REFERÊNCIAS}

AGAMBEN, Giorgio. A potência do pensamento: ensaios e conferências. Tradução de António Guerreiro. Belo Horizonte: Editora Autêntica, 1975.

ALBUQUERQUE, Ana Lídia de Oliveira. Política, poética e performance no espaço religioso: estudo da cultura material da Igreja Metodista Central em Santo André. 2018. Dissertação (Mestrado em Ciências da Religião) - Universidade Metodista de São Paulo, São Bernardo do Campo, 2018.

AUSTIN, John L. How to do things with words. Cambridge: Harvard University Press, 1962.

BAITELLO JUNIOR, Norval. A era da iconofagia: reflexões sobre a imagem, comunicação, mídia e cultura. São Paulo: Paulus, 2014.

BAITELLO JUNIOR, Norval. Para que servem as imagens mediáticas? Os ambientes culturais da comunicação, as motivações da iconomania, a cultura da visualidade e suas funções. In: Trabalho apresentado ao Grupo de Trabalho "Comunicação e Cultura”, do XVI Encontro da Compós, na UTP, em Curitiba, PR, em junho de 2007. Disponível em:

<https://www.cisc.org.br/portal/jdownloads/BAITELLO\%20JUNIOR\%20Norval/para_q ue_servem_as_imagens_mediticas.pdf >.Acesso em: 12 set. 2018.

BARTMANSKI, Dominik. The word/image dualism revisited: Towards an iconic conception of visual culture. Journal of Sociology, v. 5O, n. 2, p. 164-181, 2014.

BELTING, Hans (ed.). Bilderfragen. Die Bildwissenschaften im Aufbruch. Munich: Wilhelm Fink Verlag, 2007.

BELTING, Hans. A verdadeira imagem. Entre a fé e a suspeita das imagens - cenários históricos. Porto: Dafne Editora, 2011.

BELTING, Hans. Bild und Kult.Eine Geschichte des Bildes vor dem Zeitalter der Kunst. Munich: C. H. Beck, 1990.

BELTING, Hans. Antropologia da imagem: para uma ciência da imagem. Lisboa: KKYM, 2001.

BELTING, Hans. Bild-Anthropologie: Entwürfe für eine Bildwissenschaft.München: Wilhelm Fink, 2001.

BENEDICT, Anderson. Comunidades imaginadas: reflexões sobre a origem e a difusão do nacionalismo. Tradução de Denise Bottman. São Paulo: Companhia das Letras, 2008.

BOEHM, Gottfried. Was ist ein Bild? Munich: Wilhelm Fink, 1994. 
BOER, Wietse de; ENENKEL, Karl; MELION, Walter. Jesuit image theory. Leiden: Brill, 2016.

BREDEKAMP, Horst. Teoria do acto icónico. Tradução de Artur Morão. Lisboa: KKYM, 2015.

BREDEKAMP, Horst. Theorie des Bildakts. 3. ed. Tradução de Artur Morão. Berlin: Suhrkamp, 2013.

BURKE, Peter Burke. A cultura popular na idade moderna: Europa, 1500-1800, Tradução de Denise Bottmann. São Paulo: Companhia das Letras, 2010.

CAMURÇA, Marcelo. Ciências sociais e ciências da religião: polêmicas e interlocuções. São Paulo: Paulinas, 2008.

CROATTO, José Severino. As linguagens da experiência religiosa: uma introdução à fenomenologia da religião. Tradução de Carlos Mario Vasquez Gutierrez. São Paulo: Paulinas, 2001. (Religião e cultura).

CRUZ, Eduardo Ribeiro da; MORI, Geraldo de (org.). Teologia e ciências da religião: a caminho da maioridade acadêmica no Brasil. São Paulo: Paulinas; Belo Horizonte: Editora PUC-Minas, 2001.

ECO, Umberto. O mito do Superman (1970). In: ECO, Umberto. Apocalípticos e integrados. 5. ed. São Paulo: Perspectiva, 2000. p. 239-280.

ENGLER, Steven; STAUBERG, Michael. Metodologia em Ciência da Religião. In: PASSOS, João D.; USARSKI, Frank (org.). Compêndio de Ciência da Religião. São Paulo: Paulinas: Paulus, 2013.

FOUCAULT, Michel. Isto não é um cachimbo. 3. ed. Rio de Janeiro: Paz e Terra, 2002.

FREEDBERG, David. The Power of Images. Studies in the History and Theory of Response. Chicago: University of Chicago Press, 1989.

HEILMAIR, Alex Florian. Imagem e força da imaginação em Hans Belting e Dietmar Kamper: possíveis contribuições da antropologia histórica para uma nova teoria da imagem. In: V Congresso Internacional de Comunicação e Cultura, São Paulo, 2015 .

HIGUET, Etienne Alfred. Contribuição dos estudos da cultura visual para as ciências da religião. In: SILVEIRA, Emerson José Sena da (org.). Como estudar as religiões: metodologias e estratégias. Petrópolis: Vozes, 2018. p. 126-160.

HUPPAUF, Bernd; WULF, Christoph (ed.). Dynamics and Performativity of Imagination: The Image between the visible and the Invisible. New York: Routledge Taylor and Francis, 2009. 
IZIDORO, José Luiz. Narrativas apócrifas e linguagem religiosa como memória e sentidos das comunidades cristãs primitivas, pela égide das teorias da linguagem. Horizonte, Belo Horizonte, v. 14, n. 42, p. 262-283, abr./jun. 2016.

KAMPER, Dietmar. Bildstörung. Im Orbit des Imaginären. Stuttgart: Cantz, 1994.

KAMPER, Dietmar. Hieroglyphen der Zeit: Texte vom Fremdwerden der Welt. Munique: Hansen, 1988.

KAMPER, Dietmar. Horizontwechsel: die Sonne neu jeden Tag, nichts neues unter der Sonne, aber. Munique: Wilhelm Fink, 2001.

KAMPER, Dietmar. Zur Geschichte der Einbildungskraft. Munique: Carl Hanser, 1981.

KONINGS, Johan. Linguagens religiosas e narrativas sagradas. Horizonte, Belo Horizonte, v. 14, n. 42, p. 236-239, abr./jun. 2016.

MALINOWSKI, Bronislaw. Magic, science and religion. Eastford, CT: Martino Fine Books, 2015.

MARANHÃO FILHO, Eduardo Meinberg de Albuquerque (org.). (Re)conhecendo o Sagrado. Reflexões teórico-metodológicas dos estudos de religiões e religiosidades. São Paulo: Fonte Editorial, 2013. (Coleção Estudos da religião).

McLUHAN, Marshall. Os meios de comunicação como extensões do homem. São Paulo: Editora Cultrix, 1969.

MIRANDA, Júlia. Carisma, sociedade e política: novas linguagens do religioso e do político. Rio de Janeiro: Relume Dumará: Núcleo de Antropologia da Política, 1999.

(Coleção Antropologia da Política).

MITCHELL, W. J. T. What Do Pictures Want? The Lives and Loves of Images. Chicago: University of Chicago Press, 2005.

MORGAN, David. The Enchantment of Art: Abstraction and Empathy from German Romanticism to Expressionism. Journal of the History of Ideas, Pennsylvania, v. 57, n. 2, p. 317-341, Apr. 1996.

MORGAN, David. The look of the sacred. In: ORSI, Robert A. (ed.). The Cambridge Companion to Religious Studies. Cambridge: Cambridge University Press, 2014.

MORGAN, David. Visual piety: a history and theory of popular religious images. Berkeley; Los Angeles; London: University of California Press, 1999.

NOGUEIRA, Paulo Augusto de S. (org.). Linguagens da religião: desafios, métodos e conceitos centrais. São Paulo: Paulinas, 2012. 
NOGUEIRA, Paulo Augusto de Souza. Religião e linguagem: proposta de articulação de um campo complexo. Horizonte, Belo Horizonte, v. 14, n. 42, p. 240-261, abr./jun. 2016.

NOGUEIRA, Paulo Augusto de Souza. Religião e linguagem: abordagens teóricas interdisciplinares. São Paulo: Paulus, 2015.

OLIVEIRA, Danielle Neves de. Mudança de horizonte: Dietmar Kamper, um herege na cruzada do imaginário. Esferas, São Paulo, ano 3, n. 4, p. 167-173, jan.-jun. 2014.

PANOFSKY, Erwin. Iconografia e iconologia: uma introdução ao estudo da arte da Renascença. In: PANOFSKY, Erwin. Significado nas artes visuais. Tradução de Maria Clara F. Kneese e J. Guinsburg. 2. ed. São Paulo: Perspectiva, 1986. p. 47-65.

PASSOS, João Décio; USARSKI, Frank (org.). Compêndio de ciência da religião. São Paulo: Paulinas: Paulus, 2013.

RENDERS, Helmut. Artefatos, imagens e logotipos como linguagens da religião: uma proposta multidisciplinar do estudo da cultural visual religiosa brasileira. In: NOGUEIRA, Paulo Augusto de Souza (org.). Religião e linguagem: abordagens teóricas interdisciplinares. São Paulo: Paulus, 2015. p. 63-88.

RENDERS, Helmut. Deus, o ser humano e o mundo nas linguagens imagéticas da religião do coração: códigos e projetos. Pistis\&Praxis: teologia e pastoral, Curitiba, v. 1, n. 2, p. 373-413, jul./dez. 2009.

RENDERS, Helmut. Homo pictor: imaginação, ritual e aprendizado mimético no mundo globalizado - uma leitura a partir das Ciências da Religião [Resenha]. Horizonte, Belo Horizonte, v. 12, n. 34, p. 613-619, jan./jun. 2014.

RENDERS, Helmut. Introdução, aceitação e rejeição de novas celebrações no metodismo brasileiro: a história da "Celebração do Coração Aquecido" e da "Festa de Dona Susana". Interações, Belo Horizonte, v. 9, n. 16, p. 350-373, jul./dez. 2014.

RENDERS, Helmut. O fundamentalismo na perspectiva da teoria da imagem: distinções entre aproximações iconoclastas, iconófilas e iconólatras às representações do divino. Estudos de Religião, São Bernardo do Campo, ano XXII, n. 35, p. 87-107, jul./dez. 2008.

RENDERS, Helmut. O Thesenblatt “A missão mundial jesuíta” de 1664: exemplo da importância da religiocordis como linguagem da religião na iconografia jesuíta.

Horizonte, Belo Horizonte, v. 13, n. 38, p. 1021-1050, abr./jun. 2015.

RENDERS, Helmut. Resenha do livro de estudo alemão Religião - Imaginação - Estética: mundos de imaginação e sensos/sentidos em religião e cultura, editado por Lucia Traut e Annette Wilke. Estudos da Religião, São Bernardo do Campo, v. 30, n. 1, p. 211-224, jan./abr. 2016.

RENDERS, Helmut. Um novo olhar ao campo religioso a partir da cultura visual: exemplos dessa linguagem da religião e questões do método. In: SOUZA, Emerson. Arte e religião: questões, reflexões e perspectivas. São Paulo: Fonte Editorial, 2015. p. 67-84. 
RORTY, Richard (org.). The linguistic turn: essays in philosophical method. Chicago: University of Chicago Press, 1992 [1967].

ROSE, Gillian. Visual Methodologies: An Introduction to the Interpretation of Visual Materials. London; Thousand Oaks; New Delhi: SAGE Publications, 2002.

SILVEIRA, Emerson José Sena da (org.). Como estudar as religiões: metodologias e estratégias. Petrópolis: Vozes, 2018.

SILVEIRA, Emerson José Sena da. Uma metodologia para as ciências da religião? Impasses metodológicos e novas possibilidades hermenêuticas. Paralellus, Recife, v. 7, n. 14, p. 73-98, jan./abr. 2016.

SILVEIRA, Emerson Sena da; COSTA, Waldiney Rodrigues S (org.). A polissemia do sagrado: desafios da pesquisa sobre religião no Brasil. São Paulo: Fonte Editorial, 2015.

TAMBIAH, Stanley. Form and meaning of magical acts. In: HORTON, Robin; FINNEGAN, Ruth (org.). Modes of thought. Londres: Faber and Faber, 1973. p. 199-229.

TEIXEIRA, Faustino (org.). A(s) ciência(s) da religião no Brasil: afirmação de uma área acadêmica. São Paulo: Paulinas, 2001.

TRAUT, Lucia; WILKE, Annette (org.). Religion - Imagination - Ästhetik:

Vorstellungs- und Sinneswelten in Religion und Kultur. Göttingen:

Vandenhoeck\&Ruprecht, 2015. (Coletânea: Critical Studies in Religion /

Religionswissenschaft, v. 7)

USARSKI, Frank. Constituintes da Ciência da Religião. Cinco ensaios em prol de uma disciplina autônoma. São Paulo: Paulinas, 2006.

WOGAN, P. Imagined Communities Reconsidered: Is print-capitalism what we think it is? Anthropological Theory, ano 1, n. 4, p. 403-418, 2001.

WULF, Christoph. Homo pictor: imaginação, ritual e aprendizado mimético no mundo globalizado. São Paulo: Hedra, 2013.

WULF, Christoph; KAMPER, Dietmar (org.). Logik und Leidenschaft: Erträge historischer Anthropologie. Berlin: Reimers, 2002. 